\title{
Comparison of postoperative complications of ileal conduits versus orthotopic neobladders
}

\author{
Liesbeth Demaegd ${ }^{1 \#}$, Maarten Albersen ${ }^{1 \#, ~ T i m ~ M u i l w i j k ~}{ }^{1}$, Uros Milenkovic ${ }^{1}$, Lisa Moris ${ }^{1}$, \\ Wouter Everaerts ${ }^{1}$, Hendrik Van Poppel ${ }^{1}$, Frank Van der $\mathrm{Aa}^{1}$, Steven Joniau ${ }^{1 *}$, Murat Akand ${ }^{1,2 *_{\wedge}}$ \\ ${ }^{1}$ Department of Urology, University Hospitals Leuven, Leuven, Belgium; ${ }^{2}$ Department of Urology, School of Medicine, Selçuk University, Konya, \\ Turkey \\ Contributions: (I) Conception and design: M Albersen, S Joniau; (II) Administrative support: M Albersen, S Joniau; (III) Provision of study materials \\ or patients: H Van Poppel, S Joniau; (IV) Collection and assembly of data: L Demaegd, U Milenkovic, L Moris, M Akand; (V) Data analysis and \\ interpretation: L Demaegd, M Akand, T Muilwijk, M Albersen, S Joniau; (VI) Manuscript writing: All authors; (VII) Final approval of manuscript: \\ All authors. \\ \#These authors contributed equally to this work as co-first authors. \\ *These authors contributed equally to this work as co-last authors. \\ Correspondence to: Murat Akand, MD, FEBU. Department of Urology, University Hospitals Leuven, Herestraat 49, 3000 Leuven, Belgium. \\ Email: drmuratakand@yahoo.com; murat.akand@uzleuven.be.
}

Background: Radical cystectomy (RC) and urinary diversion (UD), with either an ileal conduit (IC) or an orthotopic neobladder (NB), is a complex surgery, in which various complications can occur. In this study, we compared postoperative complication rates after a RC and UD performed for the treatment of muscleinvasive bladder cancer or recurring high-risk non-muscle-invasive bladder cancer in our center.

Methods: We retrospectively included 604 patients that underwent UDs from December 1996 to August 2015. Complications were classified by type and severity according to the Clavien-Dindo classification (CDC). Univariate and multivariate analyses were performed to identify predictive factors of short-term $(\leq 30 \mathrm{~d})$, intermediate-term (31-90 d), and long-term (>90 d) complications.

Results: Four hundred and forty-five (74\%) and 159 (26\%) patients received ICs and NBs, respectively. These groups had significantly different long-term complication rates (IC: $39.7 \%$ s. NB: 49\%, P=0.046), but similar short-term $(\mathrm{P}=0.319)$ and intermediate-term complication rates $(\mathrm{P}=0.397)$. Short-term complications (CDC I-V) were predicted by male gender, age-adjusted Charlson comorbidity index (aCCI) $\geq 3$, and American Society of Anesthesiologists (ASA) score $\geq 3$. Compared to minor short-term complications (CDC I-II), major short-term complications (CDC III-V) were predicted by male gender and a previous abdominal/pelvic surgery, and long-term major complications were predicted by the type of UD (NB).

Conclusions: The increasing risk of short-term complications with increasing aCCI and ASA score can be used when counseling the patients who are planned to undergo a RC with UD. Patients that receive NBs should be informed of the increased risk of reoperations compared to an IC.

Keywords: Bladder cancer (BC); complication; ileal conduit (IC); neobladder (NB); radical cystectomy (RC)

Submitted Mar 05, 2020. Accepted for publication Sep 28, 2020.

doi: $10.21037 /$ tau-20-713

View this article at: http://dx.doi.org/10.21037/tau-20-713

^ ORCID: 0000-0001-8840-5771. 


\section{Introduction}

Bladder cancer (BC) is the 10th most common type of cancer in both sexes worldwide $(1,2)$. A radical cystectomy (RC) with lymph node dissection and urinary diversion (UD) is the treatment of choice for muscle-invasive $\mathrm{BC}$ or recurring high-risk non-muscle-invasive BC (3). Complication rates are high with RC plus UDs (RC+UDs), primarily due to the UD (4). The most common UDs are the ileal conduit (IC) and the orthotopic neobladder (NB). However, although the UD type does not affect the long-term oncological outcome, it remains unknown which UD type provides the best overall quality of life $(3,5)$. Comparisons of ICs and NBs have not demonstrated improved quality of life, but NBs might be the best option for carefully selected patients $(6,7)$. Currently, ICs are the most common UD, while the NB is primarily performed in high-volume centers due its technical complexity $(8,9)$. Only motivated patients that understand the new bladder voiding mechanism are candidates for NBs (9).

Here, we compared ICs and NBs in terms of the incidence, severity, and timing of postoperative complications. This information could facilitate decisions regarding RC+UDs. Furthermore, we identified independent risk factors for postoperative complications. We present the following article in accordance with the STROBE reporting checklist (available at http://dx.doi. org/10.21037/tau-20-713).

\section{Methods}

All procedures performed in this study working on human participants were in accordance with the ethical standards of the institutional research committee and with the 1964 Helsinki Declaration and its later amendments or comparable ethical standards. The study was approved by the Ethics Committee of UZ/KU Leuven (No. S59188). For a retrospective study, formal consent was not required. After obtaining Institutional Review Board approval, we reviewed the medical records of patients treated with open $\mathrm{RC}+\mathrm{UDs}$ performed by two experienced oncologic urologists $(\mathrm{H}$ Van Poppel, S Joniau) at the University Hospitals Leuven, between December 1996 and August 2015. Eligible patients received $\mathrm{RC}+\mathrm{UDs}$ for urothelial carcinoma. Exclusion criteria were RCs for non-oncological disorders (e.g., neurogenic bladder disease, bladder pain syndrome, radiation cystitis, disabling urinary incontinence), palliative
RCs, RCs combined with nephroureterectomy, and complete urinary tract extirpations. All IC patients received a Bricker anastomosis, and Leuven N-pouch was performed for the patients who had a NB. The technique for each UD was described previously (10-12). Briefly, Leuven N-pouch was created with a $50-\mathrm{cm}$ segment of preterminal ileum that was folded into four equally long parts. Three parts formed the $\mathrm{N}$-shaped pouch while the most proximal part remained intact to form the afferent isoperistaltic limb onto which the ureters were anastomosed in an end-to-end fashion. UD types were selected in a decision-making process shared between patients and surgeons.

The analyzed preoperative and intraoperative patient characteristics are listed in Tables 1,2. Perioperative complications were categorized with the modified ClavienDindo classification (CDC) as minor (CDC I-II) or major (CDC III-V) (13). Complications were also categorized as short-term ( $\leq 30$ days), intermediate-term (31-90 days), or long-term ( $>90$ days), based on the European Association of Urology (EAU) Guidelines recommendations on reporting surgical complications (14).

The primary endpoint was the incidence of short-, intermediate-, and long-term perioperative complications with ICs compared to NBs. Secondary endpoints were the effects of prognostic clinical and pathological characteristics on complication rates.

Age at surgery was categorized as $\leq 60,61-70$, and $\geq 71$ years. Comorbidities were categorized based on American Society of Anesthesiologists (ASA) score ( $\leq 2 \mathrm{vs}$. $\geq 3$ ), Charlson comorbidity index (CCI: 0 vs. 1 vs. 2 vs. $\geq 3$ ), and age-adjusted CCI (aCCI: $\leq 2$ vs. 3-5 vs. $>5$ ).

\section{Statistical analysis}

Descriptive statistics were expressed as the mean \pm standard deviation (SD) or the percentage for continuous and nonnumeric variables, respectively. Continuous and categorical variables were compared with the students' $t$-test and chisquared test, respectively. Significance was set at $\mathrm{P}<0.05$. Univariate and multivariate analyses were performed to identify independent predictors of complications. After performing a Pearson's correlation test, significant factors in univariate analyses were included in multivariate logistic regression models. Statistical analyses were performed with MedCalc version 16.2.1 (MedCalc Software bvba, Oostende, Belgium). 
Table 1 Preoperative characteristics according to type of UD

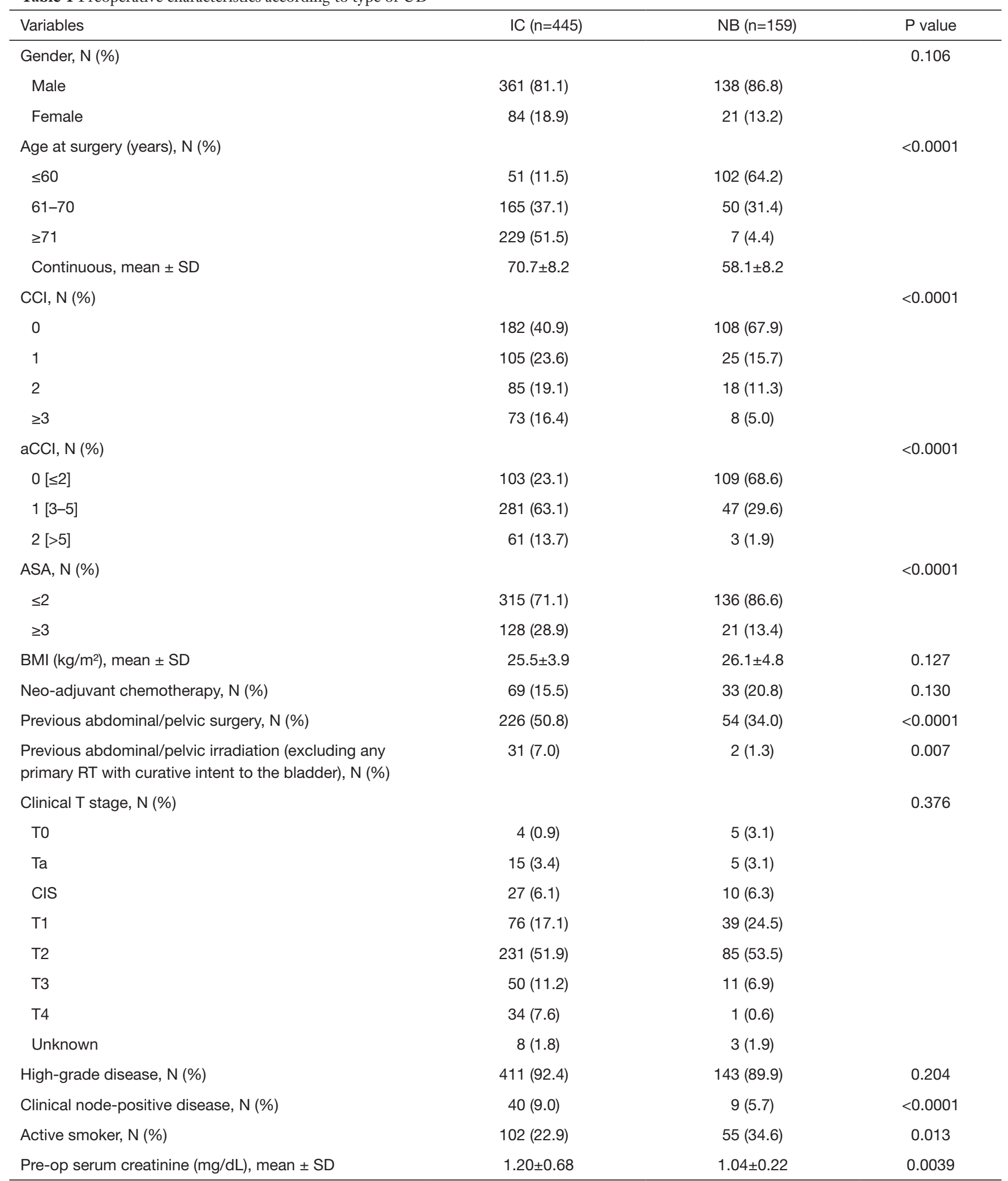

$\mathrm{CCl}$, Charlson comorbidity index; aCCl, age-adjusted Charlson comorbidity index; ASA, American Society of Anesthesiologists physical status classification system; BMI, body mass index; RT, radiotherapy; CIS, carcinoma in situ. 
Table 2 Intraoperative characteristics related to the type of UD

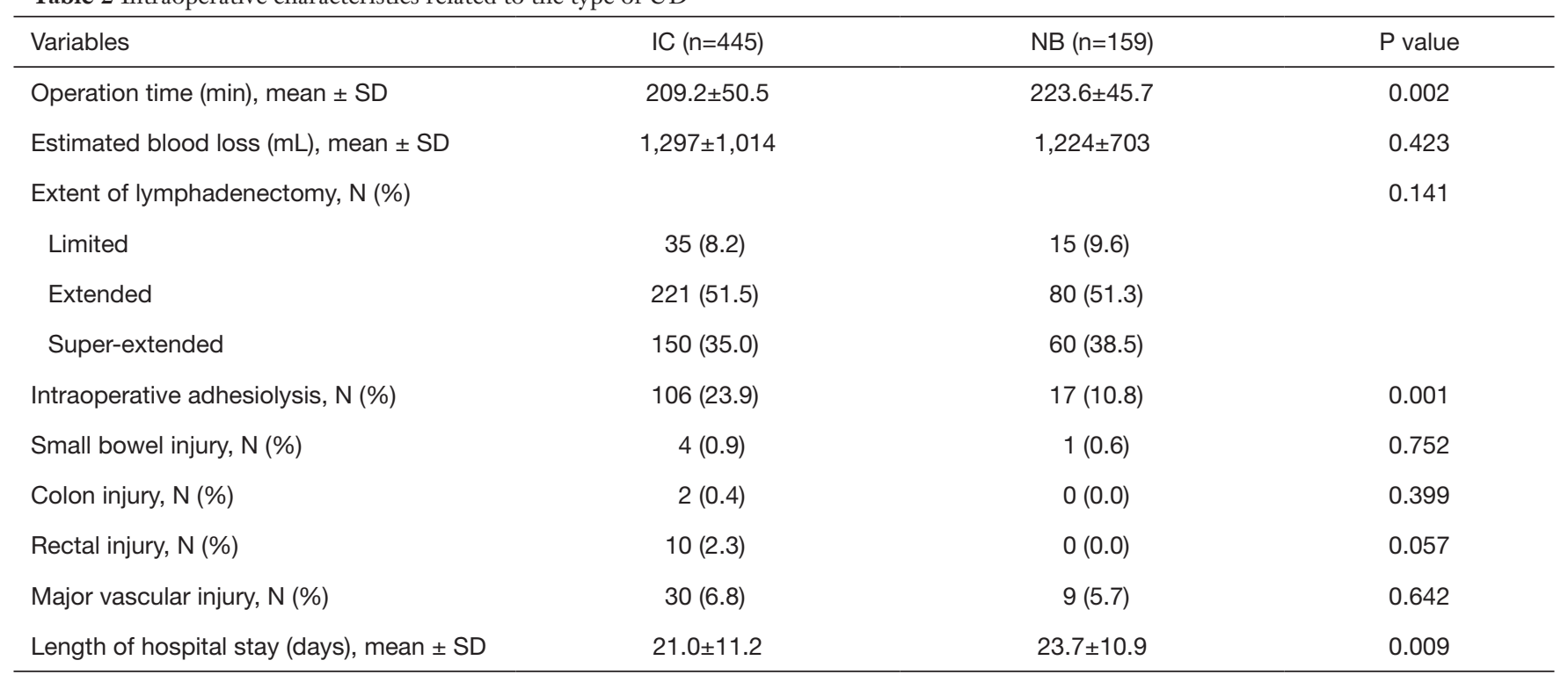

UD, urinary diversion; SD, standard deviation.

\section{Results}

\section{Clinical characteristics}

Of 927 patients that received $\mathrm{RC}+\mathrm{UDs}, 604$ were included after exclusion criteria; 445 had ICs and 159 had NBs (Table 1). The patients with ICs were significantly older and had higher CCI, aCCI and ASA scores (all: $\mathrm{P}<0.0001$ ), and more frequent previous abdominal and/or pelvic surgery $(\mathrm{P}=0.001)$ than the patients with NBs. Neoadjuvant chemotherapy (NAC) rates were similar between groups $(\mathrm{P}=0.130)$.

Due to technical complexity, NBs required longer operation times than ICs $(\mathrm{P}=0.002$; Table 2). Blood loss was similar between groups $(\mathrm{P}=0.423)$. Due to more frequent previous abdominal/pelvic surgery, ICs required intraoperative adhesiolysis more frequently than NBs $(\mathrm{P}=0.001)$.

\section{Postoperative complications}

\section{Short-term ( $\leq 30$ days) complications}

Overall, minor and major short-term complications occurred at similar rates with ICs and $\mathrm{NBs}(\mathrm{P}=0.319$, Table 3). One patient with a NB died perioperatively, due to a perforation of the small intestine, which resulted in septic shock and acute myocardial infarction.

The most common minor complications were urinary tract infection (UTI) with fever, pneumonia, superficial wound dehiscence, blood transfusion, and ileus (defined as no sign of bowel transit for $>5$ days). The most common major complications were intestinal anastomotic leakage that required a reoperation, urosepsis, re-laparotomy due to evisceration, and pulmonary infection. Among the most common complications, pulmonary, and wound-related complications occurred significantly more frequently with ICs than with NBs (Table 3).

\section{Intermediate-term (31-90 days) complications}

In the intermediate term, data were missing for 33 patients (27 ICs and $6 \mathrm{NBs}$ ), due to loss to follow-up or death. Overall, minor and major intermediate-term complications occurred at similar rates with ICs and NBs $(\mathrm{P}=0.397$, Table 4).

Most complications in both groups were of genitourinary origin, and the most common were UTIs. The most common minor complications were gastrointestinal complications in both groups, and herniations and stoma problems in the IC group. In both groups, the most common major complications were upper urinary tract (UUT) obstructions that required ureteral stenting or a nephrostomy tube insertion and fistulas that required reoperations. Total gastrointestinal, genitourinary and wound complications, and herniations were more common with NBs than with ICs. 
Table 3 Short-term ( $\leq 30$ days) complications in patients after $\mathrm{RC}$ with IC or NB

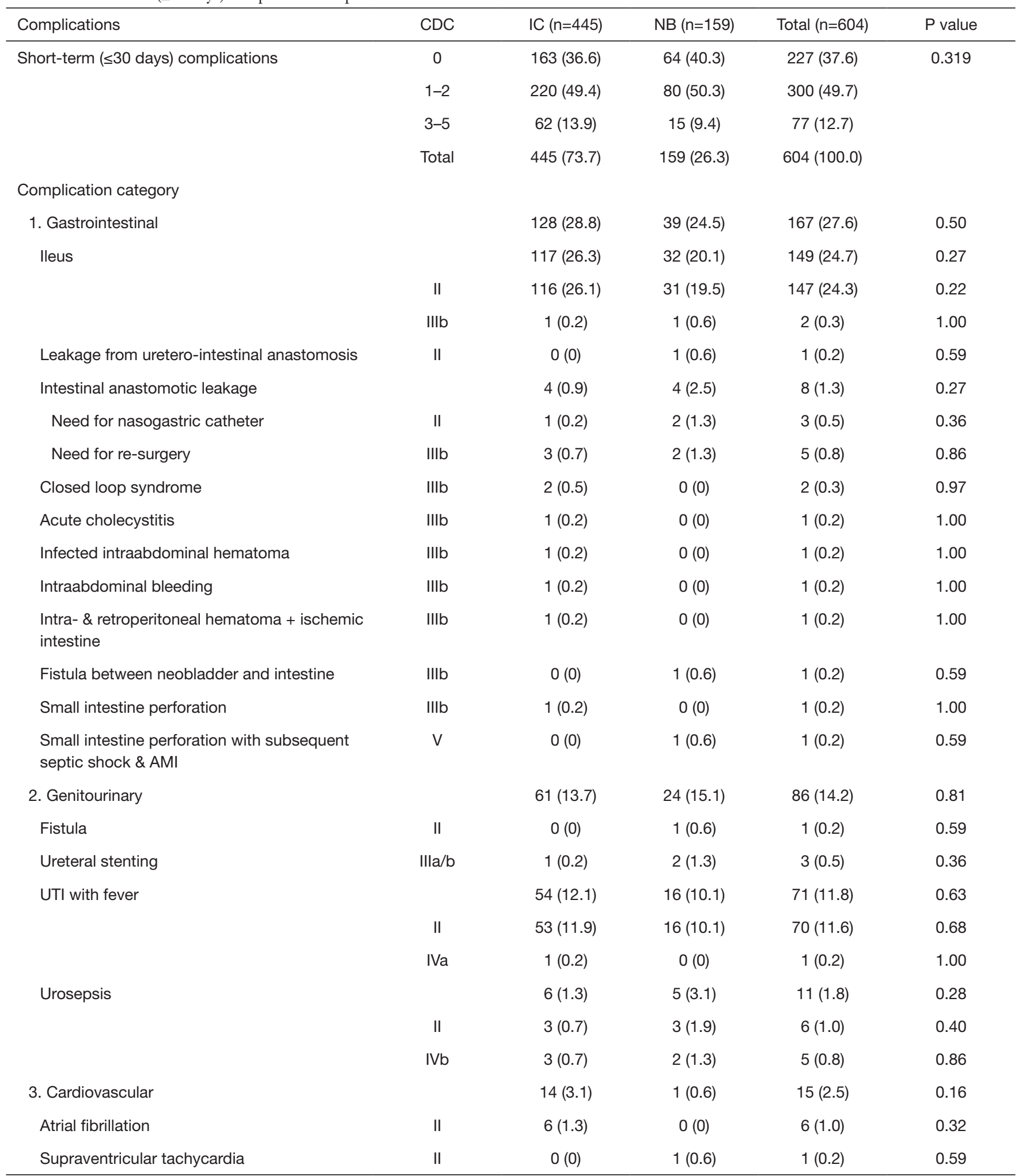

Table 3 (continued) 
Table 3 (continued)

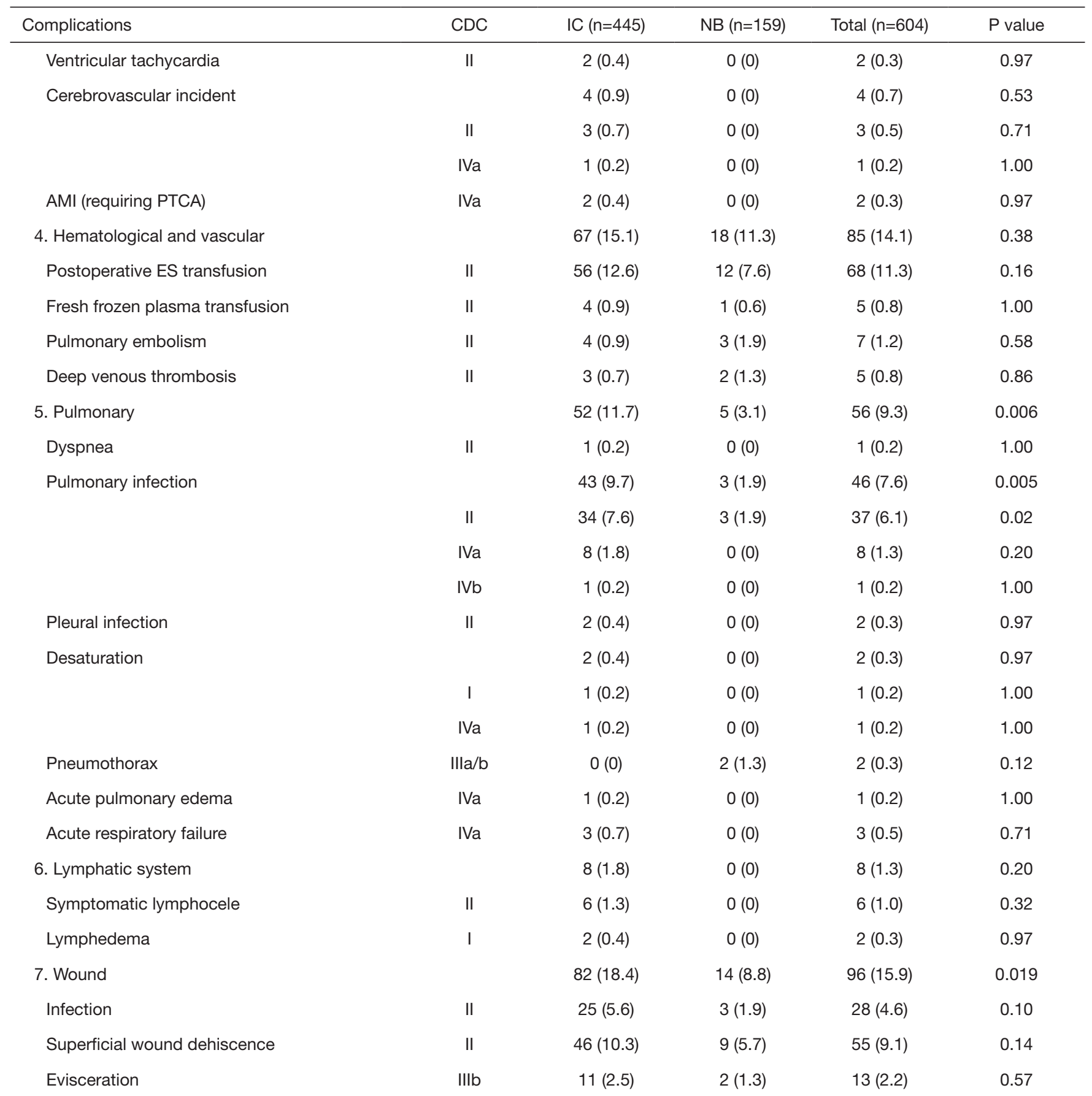

CDC, Clavien-Dindo classification; AMI, acute myocardial infarction; UTI, urinary tract infection; PTCA, percutaneous transluminal coronary angioplasty; ES, erythrocyte suspension. 
Table 4 Intermediate-term (31-90 days) complications in patients after RC with IC or NB

\begin{tabular}{|c|c|c|c|c|c|}
\hline Complications & CDC & IC $(n=418)$ & NB $(n=153)$ & Total $(n=571)$ & $P$ value \\
\hline \multirow{3}{*}{ Intermediate-term (31-90 days) complications } & $1-2$ & $88(21.1)$ & $36(23.5)$ & $124(21.7)$ & \\
\hline & $3-5$ & $28(6.7)$ & $10(6.5)$ & $38(6.7)$ & \\
\hline & Total & $418(73.2)$ & $153(26.8)$ & $571(100.0)$ & \\
\hline 1. Gastrointestinal & & $15(3.6)$ & $13(8.5)$ & $28(4.9)$ & 0.04 \\
\hline Paralytic ileus & I & $0(0)$ & $1(0.7)$ & $1(0.2)$ & 0.60 \\
\hline Persistent tenesmus & I & $0(0)$ & $1(0.7)$ & $1(0.2)$ & 0.60 \\
\hline Diarrhea & II & $3(0.7)$ & $9(5.9)$ & $12(2.1)$ & 0.0008 \\
\hline 2. Genitourinary & & $41(9.8)$ & $18(11.8)$ & $59(10.3)$ & 0.65 \\
\hline Renal function decline & I & $1(0.2)$ & $1(0.7)$ & $2(0.4)$ & 1.00 \\
\hline Hematuria & I & $1(0.2)$ & $0(0)$ & $1(0.2)$ & 1.00 \\
\hline Stone disease (spontaneous passage) & I & $1(0.2)$ & $0(0)$ & $1(0.2)$ & 1.00 \\
\hline Penile wound & I & $4(1.0)$ & $0(0)$ & $4(0.7)$ & 0.52 \\
\hline UTI with fever & II & $12(2.9)$ & $8(5.2)$ & $20(3.5)$ & 0.29 \\
\hline Balanitis (circumcision) & Illa & $1(0.2)$ & $0(0)$ & $1(0.2)$ & 1.00 \\
\hline Orchitis & II & $1(0.2)$ & $0(0)$ & $1(0.2)$ & 1.00 \\
\hline Acute renal failure & IVa & $1(0.2)$ & $0(0)$ & $1(0.2)$ & 1.00 \\
\hline 3. Wound & & $18(4.3)$ & $2(1.3)$ & $20(3.5)$ & 0.16 \\
\hline Chronic wound problems & 1 & $7(1.7)$ & $2(1.3)$ & $9(1.6)$ & 1.00 \\
\hline Decubitus wound & I & $1(0.2)$ & $0(0)$ & $1(0.2)$ & 1.00 \\
\hline Superficial dehiscence & ॥ & $2(0.5)$ & $0(0)$ & $2(0.4)$ & 0.96 \\
\hline Evisceration & $\mathrm{III} a / \mathrm{b}$ & $4(1.0)$ & $0(0)$ & $4(0.7)$ & 0.52 \\
\hline Wound infection & Illb & $4(1.0)$ & $0(0)$ & $4(0.7)$ & 0.52 \\
\hline
\end{tabular}

Table 4 (continued) 
Table 4 (continued)

\begin{tabular}{|c|c|c|c|c|c|}
\hline Complications & CDC & IC $(n=418)$ & NB $(n=153)$ & Total $(n=571)$ & $P$ value \\
\hline Incisional herniation & I & $6(1.4)$ & $3(2.0)$ & $9(1.6)$ & 0.95 \\
\hline Parastomal herniation & & $10(2.4)$ & $\mathrm{N} / \mathrm{A}$ & $10(1.8)$ & $\mathrm{N} / \mathrm{A}$ \\
\hline Conservative & 1 & $9(2.2)$ & N/A & $9(1.6)$ & $\mathrm{N} / \mathrm{A}$ \\
\hline 5. Hematological and vascular & & $3(0.7)$ & $0(0)$ & $3(0.5)$ & 0.69 \\
\hline Deep venous thrombosis & II & $2(0.5)$ & $0(0)$ & $2(0.4)$ & 0.96 \\
\hline Vaginal bleeding & I & $1(0.2)$ & $0(0)$ & $1(0.2)$ & 1.00 \\
\hline 6. Infectious (other) & & $4(1.0)$ & $2(1.3)$ & $6(1.1)$ & 1.00 \\
\hline 7. Pulmonary & & $1(0.2)$ & $0(0)$ & $1(0.2)$ & 1.00 \\
\hline Pneumonia (with MOF) & V & $1(0.2)$ & $0(0)$ & $1(0.2)$ & 1.00 \\
\hline 8. Lymphatic system & & $2(0.5)$ & $0(0)$ & $2(0.4)$ & 0.96 \\
\hline Lymphedema & I & $2(0.5)$ & $0(0)$ & $2(0.4)$ & 0.96 \\
\hline 9. Miscellaneous & & $22(5.3)$ & $3(2.0)$ & $25(4.4)$ & 0.16 \\
\hline \multirow[t]{3}{*}{ Stoma problems (irritation, etc.) } & & $12(2.9)$ & $\mathrm{N} / \mathrm{A}$ & $12(2.1)$ & N/A \\
\hline & I & $11(2.6)$ & $\mathrm{N} / \mathrm{A}$ & $11(1.9)$ & N/A \\
\hline & IIllb & $1(0.2)$ & N/A & $1(0.2)$ & N/A \\
\hline Depression & II & $1(0.2)$ & $0(0)$ & $1(0.2)$ & 1.00 \\
\hline Acute gout attack & II & $1(0.2)$ & $0(0)$ & $1(0.2)$ & 1.00 \\
\hline Neuropathic pain & II & $2(0.5)$ & $0(0)$ & $2(0.4)$ & 0.96 \\
\hline Electrolyte imbalance & 1 & $1(0.2)$ & $1(0.7)$ & $2(0.4)$ & 1.00 \\
\hline Rise in alkaline phosphatase & I & $0(0)$ & $1(0.7)$ & $1(0.2)$ & 0.60 \\
\hline Iron depletion & I & $0(0)$ & $1(0.7)$ & $1(0.2)$ & 0.60 \\
\hline
\end{tabular}

CDC, Clavien-Dindo classification; UTI, urinary tract infection; UUT, upper urinary tract; HUN, hydroureteronephrosis; LUT, lower urinary tract; FUO, fever of unknown origin; MOF, multiple organ failure; N/A, not applicable. 
Table 5 Long-term (>90 days) complications in patients after RC with IC or NB

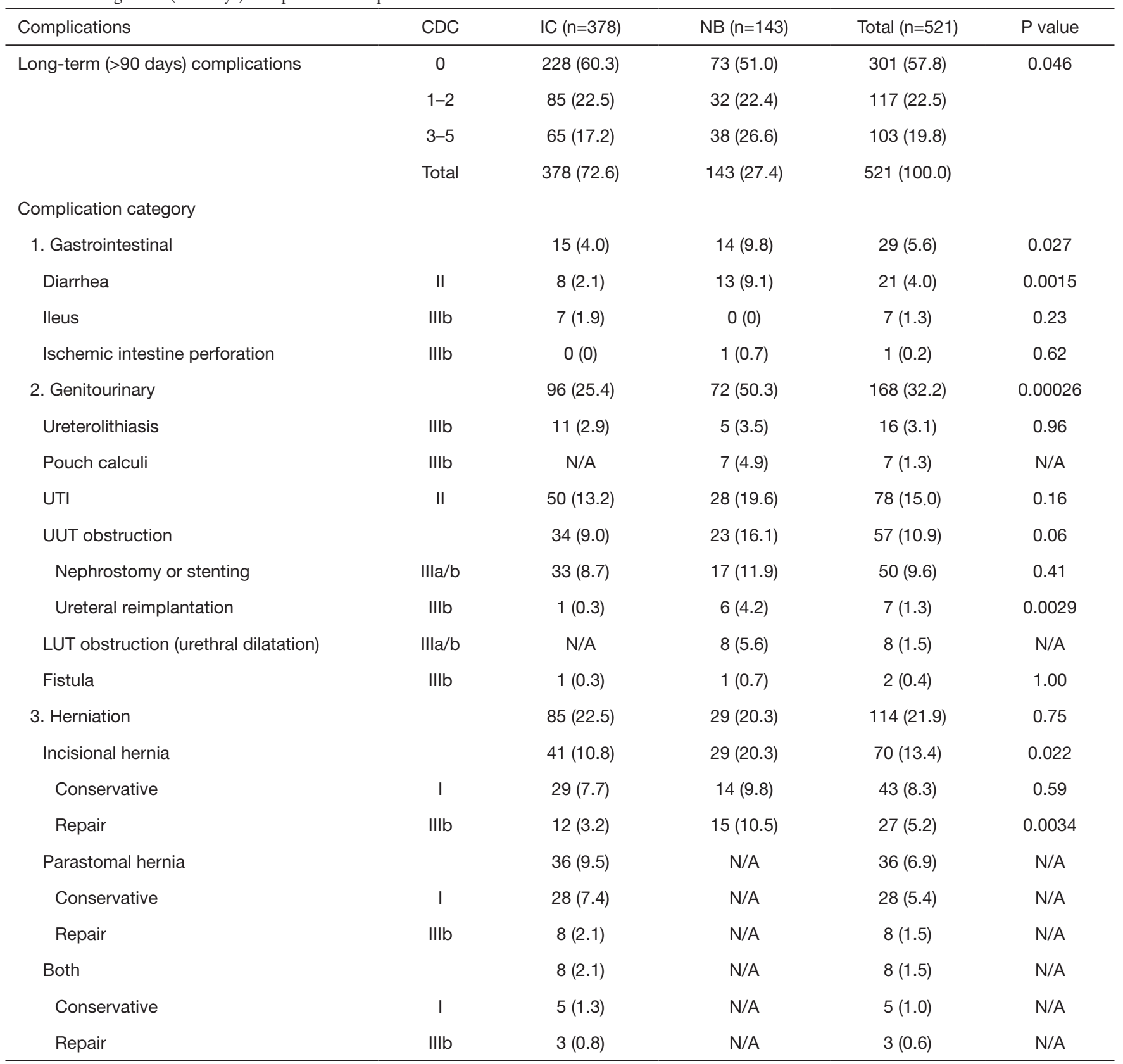

CDC, Clavien-Dindo classification; UTI, urinary tract infection; UUT, upper urinary tract; LUT, lower urinary tract; N/A, not applicable.

\section{Long-term ( $>90$ days) complications}

Overall, long-term minor complications occurred at similar rates between groups. However, major long-term complications occurred more frequently with NBs than with ICs ( $\mathrm{P}=0.046$; Table 5).

UTIs were the most common minor complication in both groups. Diarrhea was more common with NBs than with ICs.

After 3 months, major complications increased in both groups, due to UUT obstructions (CDC IIIa/b). NBs were prone to neovesicourethral anastomotic stricture (5.6\%), which required urethral dilatation due to high postvoiding residual urine volume or difficulty in voiding. Ureterolithiasis rates were comparable between groups. 
Table 6 Univariate and multivariate analysis of patients' characteristics for postoperative complications occurring on short-, intermediate- and long-term (only the significant multivariate analysis is mentioned)

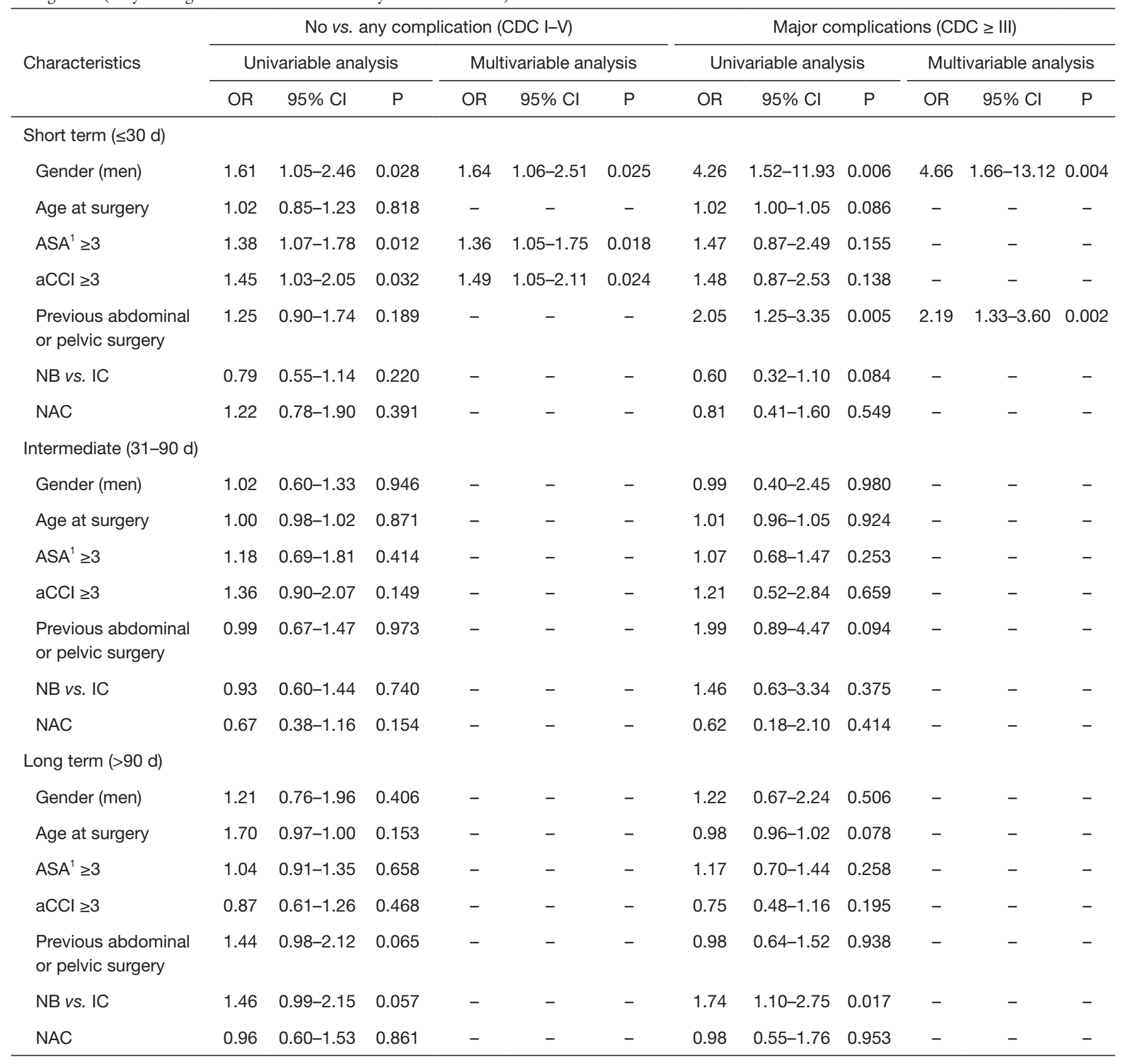

1, ASA: ASA 1-2 vs. ASA 3-4. ASA, American Society of Anesthesiologists physical status classification system, aCCl, age-adjusted Charlson comorbidity index; NAC, neoadjuvant chemotherapy; NB, neobladder; IC, ileal conduit; OR, odds ratio; Cl, confidence interval.

Pouch calculi occurred in $4.9 \%$ of NBs.

Although total herniation rates were similar between groups, incisional hernias occurred significantly more frequently with $\mathrm{NBs}$ than with ICs $(\mathrm{P}=0.022)$. In addition, ICs were prone to parastomal hernias (Table 5).

\section{Predictors of complications}

Male gender, ASA score $\geq 3$, and aCCI $\geq 3$ were independent risk factors for any short-term complications (CDC I-V) (Table 6, Figure 1). Major short-term complications were associated with male gender and previous abdominal/pelvic 


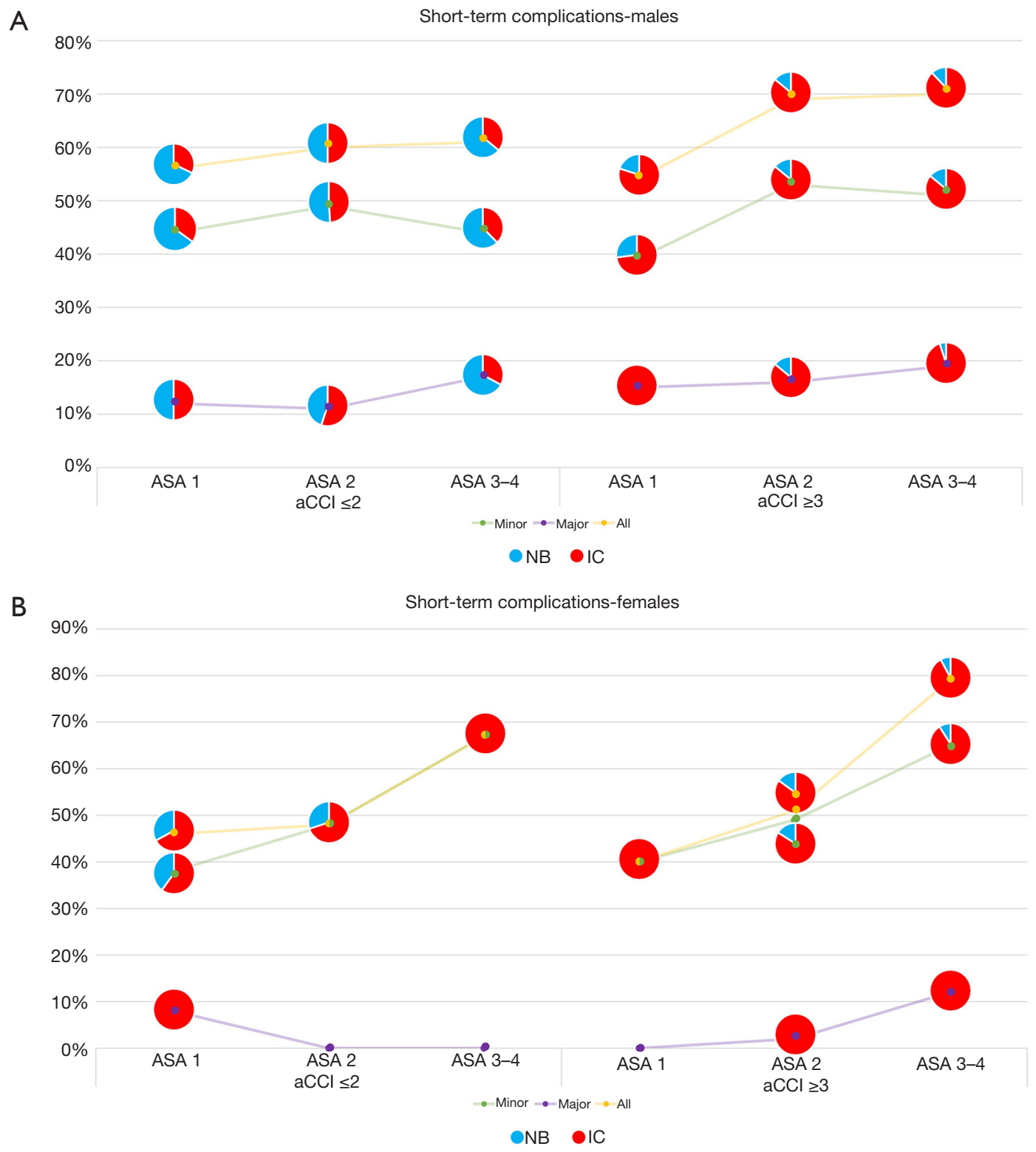

Figure 1 Short-term complication rates in males (A) and females (B) according to grouping with regard to age-adjusted Charlson comorbidity index (aCCI) and American Society of Anesthesiologists (ASA) scores. NB, neobladder; IC, ileal conduit.

surgery. None of the studied factors were associated with minor or major intermediate-term complications. Major long-term complications were associated with the NB. NAC administration did not impact the complication risk at any time.

Our reports fulfilled nine out of ten criteria that have been proposed by Martin et al. for accurate and comprehensive reporting of surgical complications (15).

\section{Discussion}

Despite recent improvements in perioperative outcomes, $\mathrm{RC}+\mathrm{UDs}$ remain associated with non-negligible morbidity and mortality (5,16-18). In a comprehensive retrospective review of $\mathrm{RC}+\mathrm{UDs}$ ( $\mathrm{n}=1,142$ patients), Shabsigh et al. showed a high overall complication rate $(64 \%)$, and $13 \%$ major complications (18). Currently, due to complexity and morbidity, NBs are performed much less frequently 
than ICs (15\% vs. $85 \%)$ (19). Two population-based observational studies showed that ICs and NBs had similar complication rates. However, those studies lacked details on BC characteristics $(20,21)$ and did not give detailed data on complications by using the previously recommended reporting guidelines (18).

Our short-term postoperative minor and major complication rates of $49.7 \%$ and $12.7 \%$, respectively, were similar to the $51 \%$ and $13 \%$, respectively, reported by Shabsigh et al. (18). Our top five short-term complications were gastrointestinal, genitourinary, wound-related, hematologic, and pulmonary in origin, consistent with previous studies $(18,22,23)$.

Figure 1 summarizes many of the important observations from this study. First of all, aCCI $\geq 3, \mathrm{ASA} \geq 3$, and male gender were independent predictors of any short-term complications. Secondly, rising aCCI and further increasing ASA score show increased risk of complications. Moreover, the age at surgery was not significantly correlated with short-term complications; therefore, aCCI might be more important/useful than biological age in selecting a UD type.

Our results were consistent with the prospective PROMETRICS 2011 study that showed aCCI $\geq 3$ and ASA score $\geq 3$ could independently predict complications after an incontinent UD (24). Although Roghmann et al. used slightly different parameters, they found that CCI $\geq 3$ predicted any and high-grade complications and ASA score $\geq 3$ predicted high-grade complications (25). Similarly, Hirobe $e t a l$. found that CCI $\geq 2$ predicted high-grade complications (26).

Although we expected to observe a difference in the complications between the patients with IC and with $\mathrm{NB}$ before our analyses, the UD type did not significantly impact any short- and intermediate-term complications. This can be explained by intuitively the right selection of patients by the surgeon, so that healthier and younger patients underwent a NB, and less healthy and older patients had an IC. However, NBs increased the relative risk of major long-term complications, including UUT obstruction, neovesicourethral stenosis, and pouch calculi (Table 5). These findings were partly contrary to previous studies, in which the UD type was not significantly associated with any complications or any major 90-day complications $(24,27)$.

There is an apparent selection bias for UD type when a patient receives preoperative radiotherapy. Only 5.4\% of the total patients in this cohort received preoperative irradiation. Moreover, patients were unequally divided between groups (7\% vs. $1.3 \%$ in IC and NB, respectively), impeding comparison between the groups. Our patients have been included in a recent paper which demonstrated that previous radiation increased the relative risk of experiencing any complication after RC (28).

Our relatively high rates of long-term complications could be attributed to dedicated, systematic data registration, performed with a method similar to that recommended by Shabsigh et al. (18). A previous abdominal/pelvic surgery increased the relative risk of major short-term complications, possibly due to intraoperative adhesiolysis.

Interestingly, during all three follow-up periods, genitourinary complications were more common with NBs than with ICs. Gastrointestinal complications, particularly diarrhea, were also more common with NBs than with ICs during the intermediate- and long-term follow-ups, but not in the short term.

We recently showed that NAC administration was not associated with short-term postoperative morbidity or mortality (29). In the present study, NAC rates were similar between groups, and they did not affect complication rates in the short, intermediate and long term.

This study had some limitations. Some data on patients and complications (particularly minor complications) might be missing, due to underreporting inherent to retrospective studies and loss to follow-up. The baseline characteristics of the IC and NB populations were quite different. We attempted to perform case-matched analysis and propensity score matching, however, the remaining populations in both groups were too small for reliable statistical analysis. Therefore, we used multivariate analysis correcting for possible confounders. However, we accept that multivariate analysis cannot fully adjust for the differences. Therefore, our results should be interpreted with caution. Ideally a formal matched analysis should be done in a larger multicenter population. The patients included in this analysis date from before the implementation of enhanced recovery after surgery (ERAS) guidelines in our institution, which explains the long hospital stay of the patients. An explicit, detailed history was recorded for all patients that returned to our center for follow-up visits. This approach might have led to more frequent detection of (minor) complications, like UTIs. The relatively long mean time to the last follow-up or death (52.6 months) might partially explain our elevated late complication rate. Moreover, our reports fulfilled 9 out of 10 criteria that have been proposed for reporting of surgical complications. These limitations and strengths should be kept in mind when interpreting the 
study results.

\section{Conclusions}

Our groups showed significantly different preoperative characteristics; therefore, we could not recommend a particular UD type as the optimal choice for the patients undergoing a RC. However, the increasing risk of shortterm complications with increasing aCCI and ASA score, as depicted in Figure 1, can be used when counseling the patients who are planned to undergo a $\mathrm{RC}$ with UD.

\section{Acknowledgments}

Murat Akand is supported by a clinical scholarship from the European Urologic Scholarship Program (EUSP). Steven Joniau is a senior clinical researcher of the Research Foundation of Flanders (FWO).

Funding: None.

\section{Footnote}

Reporting Checklist: The authors have completed the STROBE reporting checklist. Available at http://dx.doi. org/10.21037/tau-20-713

Data Sharing Statement: Available at http://dx.doi. org/10.21037/tau-20-713

Peer Review File: Available at http://dx.doi.org/10.21037/ tau-20-713

Conflicts of Interest: All authors have completed the ICMJE uniform disclosure form (available at http://dx.doi. org/10.21037/tau-20-713). The authors have no conflicts of interest to declare.

Ethical Statement: The authors are accountable for all aspects of the work in ensuring that questions related to the accuracy or integrity of any part of the work are appropriately investigated and resolved. All procedures performed in this study working on human participants were in accordance with the ethical standards of the institutional research committee and with the 1964 Helsinki Declaration and its later amendments or comparable ethical standards. The study was approved by the Ethics Committee of UZ/ KU Leuven (No. S59188). For a retrospective study, formal consent was not required.
Open Access Statement: This is an Open Access article distributed in accordance with the Creative Commons Attribution-NonCommercial-NoDerivs 4.0 International License (CC BY-NC-ND 4.0), which permits the noncommercial replication and distribution of the article with the strict proviso that no changes or edits are made and the original work is properly cited (including links to both the formal publication through the relevant DOI and the license). See: https://creativecommons.org/licenses/by-nc-nd/4.0/.

\section{References}

1. Bray F, Ferlay J, Soerjomataram I, et al. Global cancer statistics 2018: GLOBOCAN estimates of incidence and mortality worldwide for 36 cancers in 185 countries. CA Cancer J Clin 2018;68:394-424.

2. Poli G, Brancorsini S, Cochetti G, et al. Expression of inflammasome-related genes in bladder cancer and their association with cytokeratin 20 messenger RNA. Urol Oncol 2015;33:505.e1-7.

3. Witjes JA, Comperat E, Cowan NC, et al. European Association of Urology. EAU Guidelines on muscleinvasive and metastatic bladder cancer: summary of the 2013 guidelines. Eur Urol 2014;65:778-92.

4. Hautmann RE, Abol-Enein H, Davidsson T, et al. International Consultation on Urologic Disease-European Association of Urology Consultation on Bladder Cancer 2012. ICUD-EAU International Consultation on Bladder Cancer 2012: Urinary diversion. Eur Urol 2013;63:67-80.

5. Lee RK, Abol-Enein H, Artibani W, et al. Urinary diversion after radical cystectomy for bladder cancer: options, patient selection, and outcomes. BJU Int 2014;113:11-23.

6. World Health Organization (WHO) Consensus Conference on Bladder Cancer, Hautmann RE, AbolEnein H, et al. Urinary diversion. Urology 2007;69:17-49.

7. Abe T, Takada N, Shinohara N, et al. Comparison of 90-day complications between ileal conduit and neobladder reconstruction after radical cystectomy: a retrospective multi-institutional study in Japan. Int J Urol 2014;21:554-9.

8. Renzo C, Richard N. Ileal conduit as the standard for urinary diversion after radical cystectomy for bladder cancer. Eur Urol Suppl 2010;9:736-44.

9. Minervini A, Serni S, Vittori G, et al. Current indications and results of orthotopic ileal neobladder for bladder cancer. Expert Rev Anticancer Ther 2014;14:419-30.

10. Baten E, Akand M, Floyd MS Jr, et al. Evaluation 
of conservative approach in the management of ureteroenteric strictures following radical cystectomy with Bricker ileal conduit: a single-center experience. Scand J Urol 2016;50:439-44.

11. De Sutter T, Akand M, Albersen M, et al. The N-shaped orthotopic ileal neobladder: functional outcomes and complication rates in 119 patients. Springerplus 2016;5:646.

12. Akand M, Kilic O, Bocu K, et al. First experience with a new form of orthotopic ileal neobladder (Leuven $\mathrm{N}$-pouch) following radical cystectomy. Turk J Urol 2019;45:S150-5 .

13. Dindo D, Demartines N, Clavien PA. Classification of surgical complications: a new proposal with evaluation in a cohort of 6336 patients and results of a survey. Ann Surg 2004;240:205-13.

14. Mitropoulos D, Artibani W, Graefen M, et al. European Association of Urology Guidelines Panel. Reporting and grading of complications after urologic surgical procedures: an ad hoc EAU guidelines panel assessment and recommendations. Eur Urol 2012;61:341-9.

15. Martin RC 2nd, Brennan MF, Jaques DP. Quality of complication reporting in the surgical literature. Ann Surg 2002;235:803-13.

16. Hautmann RE, de Petriconi RC, Pfeiffer C, et al. Radical cystectomy for urothelial carcinoma of the bladder without neoadjuvant or adjuvant therapy: long-term results in 1100 patients. Eur Urol 2012;61:1039-47.

17. Amini E, Djaladat H. Long-term complications of urinary diversion. Curr Opin Urol 2015;25:570-7.

18. Shabsigh A, Korets R, Vora KC, et al. Defining early morbidity of radical cystectomy for patients with bladder cancer using a standard reporting methodology. Eur Urol 2009;55:164-74.

19. Gore JL, Litwin MS; Urologic Diseases in America Project. Quality of care in bladder cancer: trends in urinary diversion following radical cystectomy. World J Urol 2009;27:45-50.

20. Gore JL, Yu HY, Setodji C, et al. Urinary diversion and morbidity after radical cystectomy for bladder cancer.

Cancer 2010;116:331-9.

Cite this article as: Demaegd L, Albersen M, Muilwijk T, Milenkovic U, Moris L, Everaerts W, Van Poppel H, Van der Aa F, Joniau S, Akand M. Comparison of postoperative complications of ileal conduits versus orthotopic neobladders. Transl Androl Urol 2020;9(6):2541-2554. doi: 10.21037/tau-20-713
21. Roghmann F, Becker A, Trinh QD, et al. Updated assessment of neobladder utilization and morbidity according to urinary diversion after radical cystectomy: A contemporary US-population-based cohort. Can Urol Assoc J 2013;7:E552-60. Erratum in: Can Urol Assoc J 2013;7:E780.

22. Hautmann RE, de Petriconi RC, Volkmer BG. Lessons learned from 1000 neobladders: the 90-day complication rate. J Urol 2010;184:990-4.

23. Takada N, Abe T, Shinohara N, et al. Peri-operative morbidity and mortality related to radical cystectomy: a multi-institutional retrospective study in Japan. BJU Int 2012;110:E756-64.

24. Schmid M, Rink M, Traumann M, et al. PROMETRICS 2011 Research Group. Evidence from the 'Prospective MulticEnTer Radical Cystectomy Series 2011 (PROMETRICS 2011)' study: how are preoperative patient chracteristices associated with urinary diversion type after radical cystectomy for bladder cancer? Ann Surg Oncol 2015;22:1032-42.

25. Roghmann F, Trinh QD, Braun K, et al. Standardized assessment of complications in a contemporary series of European patients undergoing radical cystectomy. Int J Urol 2014;21:143-9.

26. Hirobe M, Tanaka T, Shindo T, et al. Complications within 90 days after radical cystectomy for bladder cancer: results of a multicenter prospective study in Japan. Int J Clin Oncol 2018;23:734-41.

27. Antonelli A, Belotti S, Cristinelli L, et al. Comparison of perioperative morbidity of radical cystectomy with neobladder versus ileal conduit: a matched pair analysis of 170 patients. Clin Genitourin Cancer 2016;14:244-8.

28. Gontero P, Pisano F, Palou J, et al. Complication rate after cystectomy following pelvic radiotherapy: an international, multicenter, retrospective series of 682 cases. World J Urol 2020;38:1959-68.

29. Milenkovic U, Akand M, Moris L, et al. Impact of neoadjuvant chemotherapy on short-term complications and survival following radical cystectomy. World J Urol 2019;37:1857-66. 